\title{
Long-term experience with intraoperative microrecording during DBS neurosurgery in STN and GPi
}

\author{
Lo J. Bour • M. Fiorella Contarino • Elisabeth M. J. Foncke • Rob M. A. de Bie • \\ Pepijn van den Munckhof • Johannes D. Speelman • P. Richard Schuurman
}

Received: 1 April 2010 /Accepted: 30 September 2010 /Published online: 15 October 2010

(C) The Author(s) 2010. This article is published with open access at Springerlink.com

\begin{abstract}
Background Intraoperative microelectrode recording (MER) for targeting during deep brain stimulation (DBS) procedures has been evaluated over a period of 4 years, in 57 consecutive patients with Parkinson's disease, who received DBS in the subthalamic nucleus (STN-DBS), and 28 consecutive patients with either dystonia (23) or Parkinson's disease (five), in whom the internal segment of the globus pallidus (GPi-DBS) was targeted.

Methods The procedure for DBS was a one-stage bilateral stereotactic approach using a combined electrode for both MER and macrostimulation. Up to five micro/macroelectrodes were used in an array with a central, lateral, medial, anterior, and posterior position. Final target location was based on intraoperative test stimulation.

Findings For the STN, the central trajectory was chosen for implantation in $50 \%$ of the cases and for the globus pallidus internus (GPi) in $57 \%$ of the cases. Furthermore, in $64 \%$ of
\end{abstract}

L. J. Bour · M. F. Contarino - R. M. A. de Bie - J. D. Speelman Department of Neurology/Clinical Neurophysiology,

University of Amsterdam,

Amsterdam, The Netherlands

P. van den Munckhof P. R. Schuurman

Department of Neurosurgery of the Academic Medical Center,

University of Amsterdam,

Amsterdam, The Netherlands

E. M. J. Foncke

Department of Neurology, Free University of Amsterdam,

Amsterdam, The Netherlands

L. J. Bour $(\bowtie)$

Department of Neurology/Clinical Neurophysiology,

D2-108, Academic Medical Center,

Meibergdreef 9,

1105 AZ Amsterdam, The Netherlands

e-mail: bour@amc.nl the cases, the channel selected for the permanent electrode corresponded with the trajectory having the longest segment of STN MER activity. For the GPi, this was the case in $61 \%$. The mean and standard deviation of the deepest contact point with respect to the magnetic resonance imaging (MRI)-based target for the STN was $2.1 \pm$ $1.5 \mathrm{~mm}$ and for the GPi was $-0.5 \pm 1.2 \mathrm{~mm}$.

Conclusions MER facilitates the selection of the final electrode location in STN-DBS and GPi-DBS, and based on the observed MER activity, a pre-selection could be made as to which channel would be the best candidate for macro-test stimulation and at which depth should be stimulated. The choice of the final location is based on intraoperative test stimulation, and it is demonstrated that regularly it is not the central channel that is chosen for implantation. On average, the target as defined by MER activity intensity was in accordance with the MRI-based targets both for the STN and GPi. However, the position of the best MER activity did not necessarily correlate with the locus that produced the most beneficial clinical response on macroelectrode testing intraoperatively.

Keywords Intraoperative microelectrode recordings · Deep brain stimulation - Globus pallidus · Subthalamic nucleus ·

Stereotactic neurosurgery

\section{Introduction}

Intra-operative microelectrode recording (MER) has been introduced to improve the target localization during stereotactic surgery $[4,21,24]$. Benabid developed a holder with five parallel channels for micro/macro needles $[2,3]$. The needle for MER, which is incorporated in the electrode for test stimulation, is able to pick up electrical activity of 
individual neurons close to the electrode due to its small tip. Spike patterns for neurons situated either in the subthalamic nucleus (STN) or in the globus pallidus (GP) are characteristic, and they differ from neuronal spike patterns of the surrounding structures. This creates the possibility to demarcate the borders of both target structures [17-21, 23, 27, 30, 38-40]. Furthermore, inside the STN and the GP, a variety of neurons, laminae, and substructures can be recognized that demarcate functionally different areas [13, $14,22,25,26,31-33,35,37]$.

Although MER reveals the electrical activity and patterns of different brain (sub)structures, it is difficult to determine whether MER has a positive effect on the clinical outcome of deep brain stimulation (DBS) treatment [15, 16]. Ultimately, it would be important to know whether the use of MER has a positive effect on clinical outcome and whether the influence that MER has had on the choice of the target has been beneficial. These questions, however, are very difficult to answer since the clinical outcome is determined by many more factors than the use of MER alone. Therefore, this has not been the aim of the current study. As a first result of this longitudinal study on MER during DBS, it was investigated to what extent the use of MER influences the DBS surgical procedure. The relative contribution of the physiological data obtained by MER and the clinical data obtained by intraoperative test stimulation to the selection of the final position for implantation was evaluated. Furthermore, we examined to what extent the activity pattern obtained from the MER corresponded with the target position based solely on threedimensional magnetic resonance imaging (3D-MRI). Finally, it was studied whether the target position based on the best MER activity matched the finally chosen location for electrode implantation based on intraoperative test stimulation.

\section{Methods}

\section{Patients}

Over a period of 4 years, 57 consecutive patients with Parkinson's disease (PD) who received DBS in the subthalamic nucleus (STN-DBS) and 28 consecutive patients with either dystonia $(n=23)$ or Parkinson's disease $(n=5)$ in whom the internal segment of the globus pallidus (GPi-DBS) was targeted were included. Data of two STN patients could not be used since, in one patient with bilateral implant, only activity from the central channel was recorded, and in another patient, a large external electrical artifact was present. In 12 patients, surgery was performed unilaterally. This makes a total of 98 STN sides. Data of three globus pallidus internus (GPi) patients could not be used since, in one patient, only activity from the central channel was recorded, one patient was operated on with anesthesia, and in the recordings of the third patient, a large external electrical artifact was present. In four patients, surgery was performed unilaterally. This makes a total of 46 insertions in the GPi. All the patients gave informed consent for the surgical DBS procedure including MER. Some of the patients with Parkinson's disease included in this study were randomized to STN or GPi-DBS as part of a large multicenter clinical trial. Inclusion criteria for surgery (idiopathic Parkinson's disease with invalidating motor fluctuations) and exclusion criteria (psychosis, severe depression, dementia, general contraindications for surgery) were the same for patients allocated to STN-DBS or GPiDBS, and for patients not participating in the trial. All patients who were included in the study received surgery under local anesthesia.

\section{Surgery}

The procedure for DBS was a one-stage bilateral stereotactic approach, using frame-based 3D-MRI reconstructions for target calculations and path-planning, with MER and macro-test stimulation. The standard target coordinates used were $12 \mathrm{~mm}$ lateral to the midplane of the third ventricle, $2 \mathrm{~mm}$ posterior to the midcommissural point (MCP), and $4 \mathrm{~mm}$ below the intercommissural line (ICL) for the STN, and $21 \mathrm{~mm}$ lateral to the midplane, $2 \mathrm{~mm}$ anterior to the MCP, and $5 \mathrm{~mm}$ below the ICL for the GPi. Adjustments were made based on visual anatomy on the planning MRI if necessary. The paths for the central channel were defined using the following criteria: anterior angulation to ICL of $15-20^{\circ}$, lateral angulation from midline $20-30^{\circ}$, entry on top of a gyrus, and avoiding sulci, cortical surface veins, and the lateral ventricles. In bilateral cases, surgery started on the left side. Three to five steel cannulas and microelectrodes were inserted through a $12-\mathrm{mm}$ diameter precoronal burr hole. All steel cannulas stayed in place throughout the surgical procedure to prevent brain displacement during surgery and to prevent choosing the wrong tract during final electrode implantation. The implanted electrodes were model 3389 (Medtronic, Minneapolis, MN, USA) with four platinumiridium cylindrical surfaces $(1.3 \mathrm{~mm}$ diameter and $1.5 \mathrm{~mm}$ length) and with an intercontact separation of $0.5 \mathrm{~mm}$. Contact 0 was the most distal, and contact 3 was the most proximal. All patients included in this study were awake during the surgical procedure, and none of them were under sedatives. In PD patients, surgery and MER were performed following overnight withdrawal of antiparkinsonian medication. To verify electrode position, patients underwent postoperative frame-based stereotactic $\mathrm{X}$-ray or postoperative frame-based stereotactic computed tomography $(\mathrm{CT})$. 
Microelectrode recording

To perform MER in STN-DBS, five MER/macrostimulation needles were placed in an array with a central, lateral, medial, posterior, and an anterior position placed $2 \mathrm{~mm}$ apart, to delineate the borders of the nucleus. Depending on the preoperative MRI, it was decided in some cases to record with three or four microelectrodes rather than five. In GPi-DBS, based on the pre-operative MRI and the better visibility of the GP structures and internal capsule, usually three to four channel recordings were performed in the central, medial, posterior, and lateral channel to define the distance of the calculated target to the border between GPi and the internal capsule. The anterior channel was included rarely.

Extracellular single/multi-unit MER was performed with small $(10 \mu \mathrm{m}$ width) polyamide-coated tungsten microelectrodes (Medtronic; microelectrode 291; impedance $1.1 \pm 0.4 \mathrm{M} \Omega$; measured at $220 \mathrm{~Hz}$, at the beginning of each trajectory) mounted on a sliding cannula. Signals were recorded with the amplifiers (10,000 times amplification) of the Leadpoint system (Medtronic), using a bootstrapping principle and were analog bandpass filtered between 500 and $5,000 \mathrm{~Hz}(-3 \mathrm{~dB} ; 12 \mathrm{~dB} / \mathrm{oct})$. The signal was sampled at $12 \mathrm{kHz}$, by use of a 16-bit $\mathrm{AD}$ converter and afterwards up-sampled to $24 \mathrm{kHz}$ off-line. Following a 2-s signal stabilization period after electrode movement cessation, multi-unit segments were recorded for 5-20 s.

Starting for STN and GPi, respectively, 8 and $12 \mathrm{~mm}$ above the MRI-based target, the microelectrodes were advanced in steps of $500 \mu \mathrm{m}$ towards the target by a manual microdrive. When the needles were inside the STN, GPe (globus pallidus externus) and GPi at each depth, the spiking activity of the neurons lying close to the needle (pick-up area up till $200 \mu \mathrm{m}$ ) could be recorded. Depending on the neuronal density not more than 3-5 units were recorded simultaneously. More distant units could not be distinguished from the background level.

\section{Positioning of DBS targets from MER}

The STN was clearly distinguished from the dorsally located zona incerta and lenticular fasciculus (field $\mathrm{H} 2$ ) by a sudden increase in background noise level and increase in discharge rate typically characterized by rhythmic bursts of activity with a burst frequency between 5 to $20 \mathrm{~Hz}$ [7]. Deeper into the STN rhythmic burst activity shifted to higher frequencies lying between 15 to $40 \mathrm{~Hz}$. Also, more irregular firing units were observed. The ventral border of the STN was recognized by a decrease of background noise and a decrease of multi-unit activity across a distance of 0.5 to $2 \mathrm{~mm}$, and, passing the ventral border of the STN, a sharp decrease in background firing was found, with more regular firing units (mean fire frequency 20 to $80 \mathrm{~Hz}$ ) of the substantia nigra (Fig. 1).
The GPe could be delineated from the dorsally located putamen by an increase in multi-unit firing activity at a depth varying from -12 to $-9 \mathrm{~mm}$ from the MRI-based target. At advancing depth between -7 to $-5 \mathrm{~mm}$, the medial medullary lamina separating the GPe from the GPi was reached. The presence of this lamina was characterized by a decrease in electrical activity and had a thickness of 1 to $2 \mathrm{~mm}$. In the vicinity of the medial medullary lamina, border cells were often recorded with a tonic regular discharge frequency between 5 to $30 \mathrm{~Hz}$. The GPi was usually more densely packed with neurons reflected by a more intense multi-unit activity than observed in the GPe. Also, bursting and pausing activity (dystonia) and tremor-related (in PD) activity were frequently observed in the GPi. Within the GPi, regularly, another lamina at about $-2 \mathrm{~mm}$ could be observed. The bottom of the GPi was recognized by a sudden decrease in background noise and multi-unit activity as the optic tract was approached (Fig. 2). Data segments were analyzed off-line for stability by visual inspection. When instability or movement/vibration or electrical artifacts were observed, the longest stable section was selected from the recording, discarding the rest.

\section{Macro-test stimulation}

After MER, the tip of the microelectrode was retracted. Channels that showed significant multi-unit activity over a length longer than $3 \mathrm{~mm}$ were selected for intraoperative test stimulation $(60 \mu$ s pulse-duration; $130 \mathrm{~Hz}$ pulsefrequency). The complete electrode with the macro-tip was then advanced to be used for macro-test stimulation, and this was performed by an experienced neurologist at two or three depths with a 2-mm interval, all within the boundaries of the target nucleus as determined by MER. After evaluation of the selected channels by macro-test stimulation, the one with the largest therapeutic window, i.e., lowest current threshold for improvement of symptoms and highest threshold for side effects, was chosen for permanent electrode implantation. For dystonic patients, the threshold for capsular side effects was used to select the best electrode. In addition, improvement of mobile dystonia was sought when present.

With respect to depth of implantation of the electrodes in STN-DBS, it is our custom to implant contact number 1 at the point with best stimulation parameters, with the deepest contact $2 \mathrm{~mm}$ below this optimal point. For GPi-DBS, we position the deepest contact point at the inferior border of the nucleus as determined by MER.

Statistical analysis

In bilateral operated patients, the choice of channel for final electrode impantation (central versus non-central) from the 


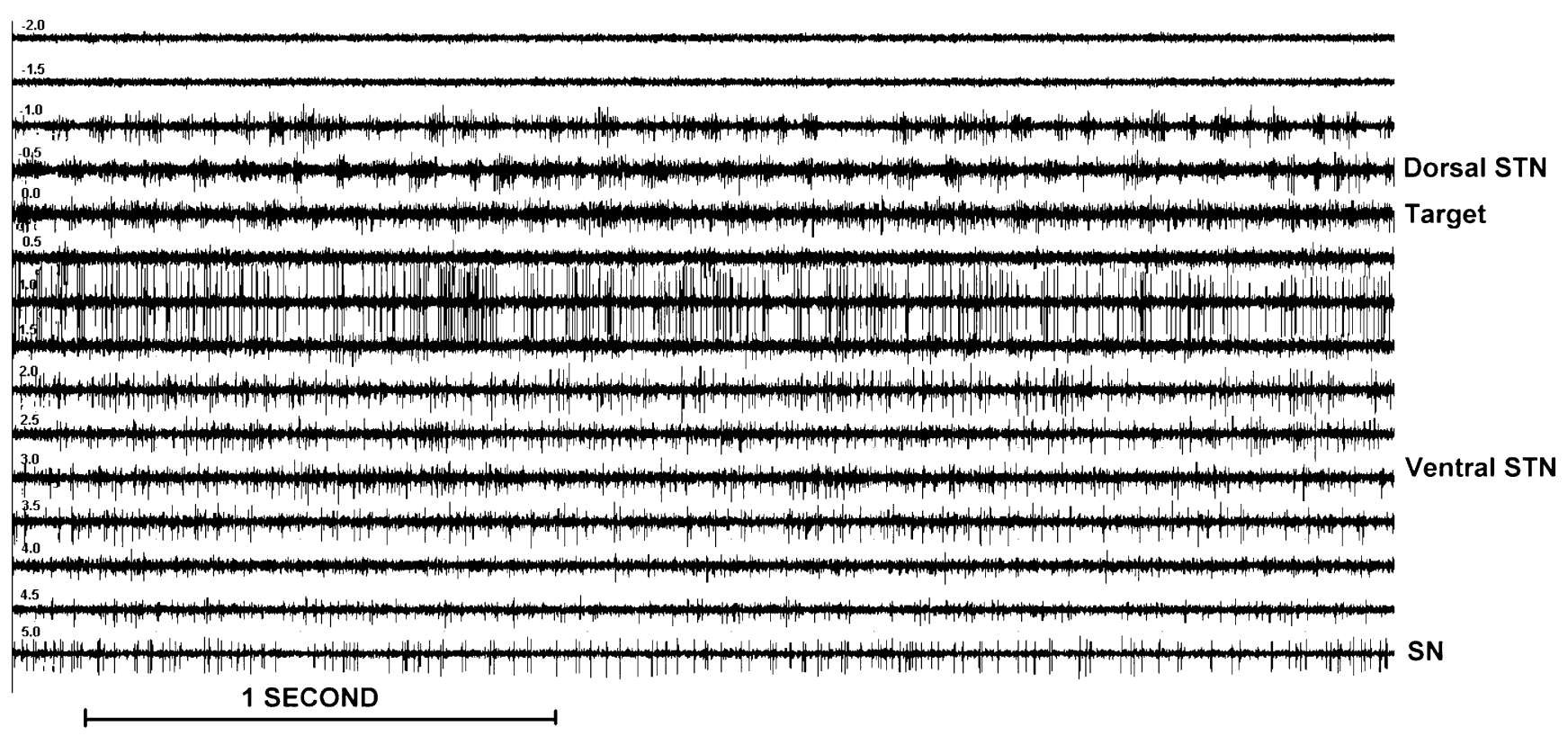

Fig. 1 Single/multi-unit activity of STN for various depths ( -2 to $+5 \mathrm{~mm})$. Note that the negative values correspond with positions above the target. The superficial part of the STN ( -1 to $0 \mathrm{~mm}$ ) is clearly recognized by an increase in background noise and a sudden increase in discharge rate

operated side first (left) and second (right) was compared using the McNemar's test. Similarly, the implantation depth of the final electrode was compared with the Student's $t$ test. Histograms of distributions and their standard deviations as well as linear regressions were calculated with Microsoft Excel. characterized by rhythmic bursts of activity in this case from 15 to $25 \mathrm{~Hz}$. Deeper layers of the STN (+1.5 to $3.5 \mathrm{~mm})$ show a more irregular highfrequency discharge pattern. SN activity $(+5 \mathrm{~mm})$ consists of a lowfrequency tonic discharge

\section{Results}

Microelectrode recording

All STN and GPi insertions showed, at least on one channel, MER activity. However, for the STN in nine out of

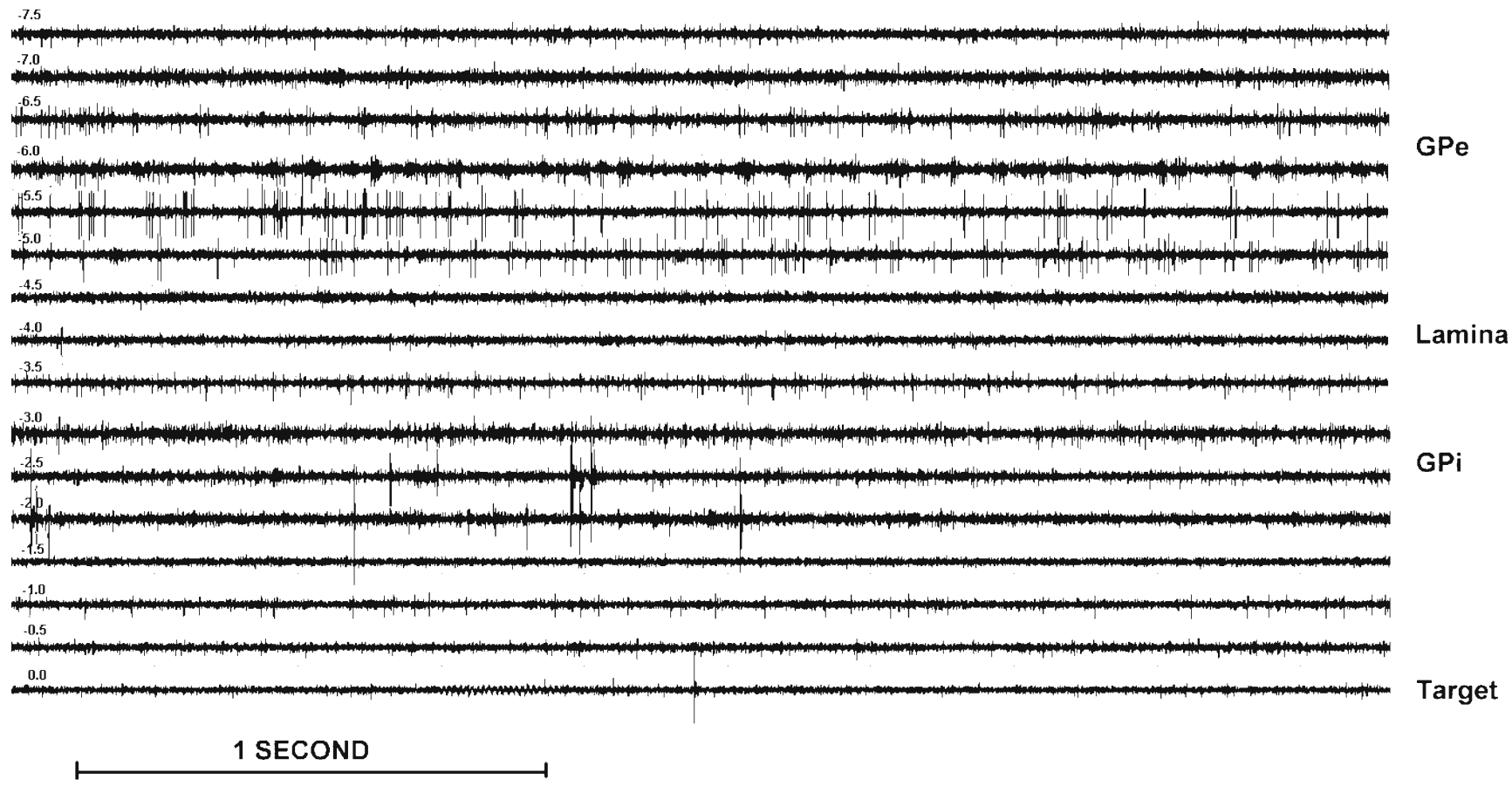

Fig. 2 Single/multi-unit activity of GPi for various depths $(-7.5$ to $0 \mathrm{~mm})$. Note that the negative values correspond with positions above the MRI-based target. At -4.5 and $-4 \mathrm{~mm}$ clearly, the lamina between the external and internal segment of the GP can be observed. The bottom of the GPi is reached at $0 \mathrm{~mm}$ 
98 cases $(9 \%)$ and for the GPi in one out of 48 cases ( $2 \%)$, no MER activity was recorded at the central channel.

Tables 1 (STN) and 2 (GPi) show the frequency distribution of the final choice for permanent electrode implantation in the central, lateral, medial, anterior, or posterior channels based on MER and macro-test stimulation, as well as the distribution of the channels in which the best MER was observed, i.e., the longest trajectory with STN or GPi neuronal activity. The central channel was chosen for implantation of the permanent electrode in 50\% of the STN and in $57 \%$ of the GPi cases. In $64 \%$ of the STN cases and in $61 \%$ of the GPi cases, the channel with the best MER activity was also chosen for implantation of the permanent electrode. In case the central electrode was selected for implantation of the electrode, this was also the channel with best MER in $78 \%$ for STN and in $76 \%$ for GPi. The final electrode position in the STN, if not placed in the central channel, was more often lateral than medial to the calculated target $[10 \%(10 / 98)$ lateral; $6 \%(6 / 98)$ medial] and more often anterior [24\% (22/98)] than posterior [(10\% (10/98)]. Best MER activity for the STN was also found more lateral than medial and more anterior than posterior from the calculated target. The final electrode position for the GPi had the tendency to go more laterally than medially. Although in the GPi, MER activity was highest at the posterior electrode in $20 \%(9 / 46)$ of the cases, due to side effects with macro-test stimulation in only two

Table 1 Comparison between the channel with the best MER activity and the channel finally chosen for permanent stimulation in the STN

\begin{tabular}{lccc}
\hline Results STN & Right $(n=47)$ & Left $(n=51)$ & Total $(n=98)$ \\
\hline Final electrode & & & \\
Central & $47 \%(22)$ & $55 \%(28)$ & $50 \%$ \\
Medial & $8.5 \%(4)$ & $4 \%(2)$ & $6 \%$ \\
Lateral & $15 \%(7)$ & $6 \%(3)$ & $10 \%$ \\
Anterior & $25.5 \%(12)$ & $20 \%(10)$ & $24 \%$ \\
Posterior & $4 \%(2)$ & $15 \%(8)$ & $10 \%$ \\
Best electrode & & & \\
Central & $47 \%(22)$ & $47 \%(24)$ & $47 \%$ \\
Medial & $13 \%(6)$ & $4 \%(2)$ & $8 \%$ \\
Lateral & $23 \%(11)$ & $16 \%(8)$ & $20 \%$ \\
Anterior & $13 \%(6)$ & $20 \%(10)$ & $16 \%$ \\
Posterior & $4 \%(2)$ & $13 \%(7)$ & $9 \%$ \\
Final $=$ best & & & \\
Central & $77 \%(17 / 22)$ & $79 \%(19 / 24)$ & $78 \%(36 / 46)$ \\
Medial & $67 \%(4 / 6)$ & $0 \%(0 / 2)$ & $50 \%(4 / 8)$ \\
Lateral & $36 \%(4 / 11)$ & $25 \%(2 / 8)$ & $32 \%(6 / 19)$ \\
Anterior & $100 \%(6 / 6)$ & $70 \%(7 / 10)$ & $81 \%(13 / 16)$ \\
Posterior & $50 \%(1 / 2)$ & $57 \%(4 / 7)$ & $55 \%(5 / 9)$ \\
Total & $66 \%(31 / 47)$ & $63 \%(32 / 51)$ & $64 \%(63 / 98)$ \\
\hline & & &
\end{tabular}

Table 2 Comparison between the channel with the best MER activity and the channel finally chosen for permanent stimulation in the GPi

\begin{tabular}{lccc}
\hline Results GPi & Right $(n=24)$ & Left $(n=22)$ & Total $(n=46)$ \\
\hline Final electrode & & & \\
Central & $50 \%(12)$ & $64 \%(14)$ & $57 \%$ \\
Medial & $8 \%(2)$ & $18 \%(4)$ & $13 \%$ \\
Lateral & $34 \%(8)$ & $9 \%(2)$ & $22 \%$ \\
Anterior & $4 \%(1)$ & $0 \%(0)$ & $2 \%$ \\
Posterior & $4 \%(1)$ & $9 \%(2)$ & $6 \%$ \\
Best electrode & & & \\
Central & $54 \%(13)$ & $54 \%(12)$ & $54 \%$ \\
Medial & $12.5 \%(3)$ & $18 \%(4)$ & $15 \%$ \\
Lateral & $12.5 \%(3)$ & $9 \%(2)$ & $11 \%$ \\
Anterior & $0 \%(0)$ & $0 \%(0)$ & $0 \%$ \\
Posterior & $21 \%(5)$ & $18 \%(4)$ & $20 \%$ \\
Final $/$ best & & & \\
Central & $85 \%(11 / 13)$ & $67 \%(8 / 12)$ & $76 \%(19 / 25)$ \\
Medial & $33 \%(1 / 3)$ & $50 \%(2 / 4)$ & $43 \%(3 / 7)$ \\
Lateral & $100 \%(3 / 3)$ & $50 \%(1 / 2)$ & $80 \%(4 / 5)$ \\
Anterior & $0 \%(0 / 0)$ & $0 \%(0 / 0)$ & $0 \%(0 / 0)$ \\
Posterior & $20 \%(1 / 5)$ & $25 \%(1 / 4)$ & $22 \%(2 / 9)$ \\
Total & $67 \%(16 / 24)$ & $54 \%(12 / 22)$ & $61 \%(28 / 46)$ \\
\hline & & &
\end{tabular}

of nine instances, this channel was selected for permanent stimulation. The anterior channel was rarely used. In bilaterally operated STN-DBS patients, the central channel was chosen for final electrode implantation in $50 \%$ of the left STNs and $39 \%$ of the right STNs $(p=0.42)$. In bilaterally operated GPi-DBS patients, the central channel was chosen for final electrode implantation in $82 \%$ of the left GPis and $65 \%$ of the right GPis $(p=0.37)$.

The final depth of implantation relative to the MRI-based target in this study is depicted in Fig. 3. For the STN, the average depth of the deepest contact point for stimulation electrode was $2.1 \mathrm{~mm}(\mathrm{SD}=1.5 \mathrm{~mm})$ which implies an almost exact correspondence between the target calculated on the planning-MRI and the mean optimal position of contact point 1 , due to the $2 \mathrm{~mm}$ difference between the centers of two successive contact points. For the GPi, the deepest contact point was implanted on average almost at the calculated depth (mean $=-0.5 \mathrm{~mm} ; \mathrm{SD}=1.2 \mathrm{~mm}$, Fig. $3 \mathrm{~b}$ ) In summary, this implied that, in 56 out of 98 (57\%) of the STN implantations and in 39 out of $46(85 \%)$ of the GPi-implantations, the final depth of implantation was situated within a range of $\pm 1 \mathrm{~mm}$ of the MRI-based target depth. In bilaterally operated STNDBS patients, mean implantation depth for the final electrode was $2.3 \mathrm{~mm}$ below calculated target depth for the left STN and $2.6 \mathrm{~mm}$ for the right STN $(p=0.23)$. In bilaterally operated GPi-DBS patients, mean implantation depth for the final electrode was $0.71 \mathrm{~mm}$ above calculated target depth for the left GPi and $0.88 \mathrm{~mm}$ for the right GPi. 


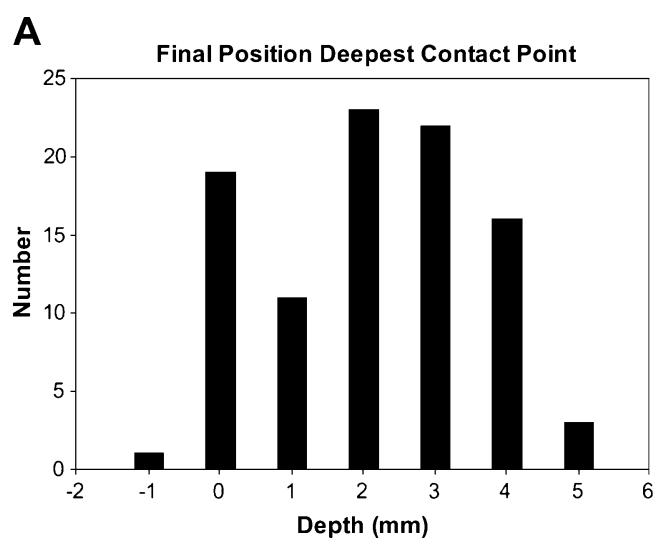

Fig. 3 a STN frequency distribution of final depth of the deepest contact point (mean=2.1 $\mathrm{mm} ; \mathrm{SD}=1.5 \mathrm{~mm}$ ) with respect to the MRIbased target. Intended coordinates: $12 \mathrm{~mm}$ lateral to midplane; $2 \mathrm{~mm}$ posterior to MCP; $4 \mathrm{~mm}$ inferior ICL. b GPi frequency distribution of

The depth position of the STN-middle with respect to the MRI-based target was calculated from the beginning and end of the STN MER activity of the channel that had the best MER activity. The mean value of the distribution was $0.0 \mathrm{~mm}$ with an SD of $1.6 \mathrm{~mm}$ (Fig. 4a). Combined with the results shown in Fig. 3a, this meant that, on average, contact point 1 was placed in the middle of the STN. From the distribution, it also followed that $27 \%$ of the STNmiddles fell outside $\pm 1.5 \mathrm{~mm}$, and only $7 \%$ fell outside the range of $\pm 3.0 \mathrm{~mm}$. Figure $4 \mathrm{~b}$ shows the comparison between the STN-middle and the final depth implantation of the deepest contact point relative to the MRI-based target, and it is demonstrated that there is a larger range ( $\pm 4 \mathrm{~mm}$ ) for the position of the STN-middle than for the finally chosen depth $(-1$ to +5$)$. A linear regression through these data for both left and right STN implantations crosses the vertical axis at about 1.9 and $2.4 \mathrm{~mm}$, respectively. This is due to the fact that the deepest contact point is always situated one contact point $(2 \mathrm{~mm})$ below the optimal position.

\section{Complications from surgery}

One patient undergoing STN-DBS postoperatively had a leftsided hemiparesis due to a right-sided subcortical hematoma. The hemiparesis completely resolved in the year following surgery. Another patient undergoing STN-DBS had a generalized seizure on postoperative day 1. CT showed bilateral subdural air, but no bleeding. No other complications were noted in the clinical records of the rest of the patients. Since we verified electrode position with postoperative frame-based stereotactic X-ray or postoperative frame-based stereotactic $\mathrm{CT}$, postoperative brain imaging of not all patients is available. Approximately half of the STN-DBS and GPi-DBS patients underwent postoperative frame-based stereotactic CT. These CTs showed variable amounts of subdural air, but no bleeding.

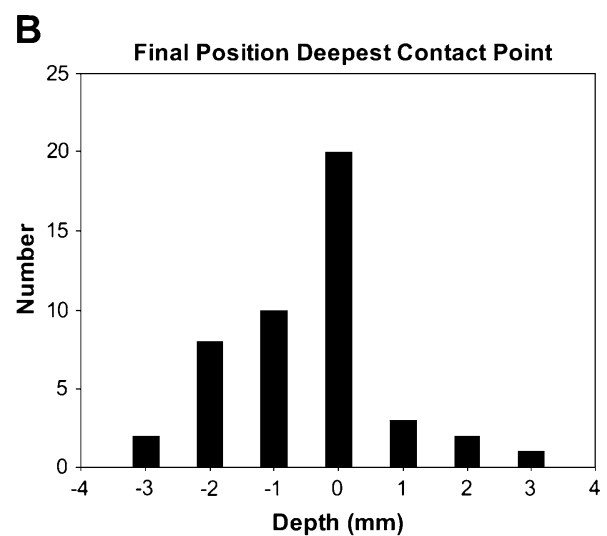

final depth of the deepest contact point (mean $=-0.5 \mathrm{~mm} ; \mathrm{SD}=1.2 \mathrm{~mm}$ ) with respect to the MRI-based target. Intended coordinates: $21 \mathrm{~mm}$ lateral to midplane; $2 \mathrm{~mm}$ anterior to $\mathrm{MCP} ; 5 \mathrm{~mm}$ inferior to $\mathrm{ICL}$

For the remaining STN-DBS and GPi-DBS patients, who only underwent postoperative frame-based stereotactic X-ray, any subclinical bleeding has remained unnoticed. The postoperative course in this last patient group was uneventful.

\section{Discussion}

The current study demonstrates that the finally chosen depth for STN-DBS coincided in $57 \%$ of the cases with the pre-operatively MRI-based target within a range of $\pm 1 \mathrm{~mm}$. For GPi-DBS, this was higher and coincided in about $85 \%$ of the cases. These percentages are higher than those found by Altermann et al. and [1] Molinuevo et al. [27]. The choice of the final target and which electrode position yielded the optimum therapeutic window was guided by the MER activity and finally determined by the results of intraoperative test stimulation. Standard deviations for the final depth of the implantations were $1.5 \mathrm{~mm}$ for the STN and $1.2 \mathrm{~mm}$ for the GPi, and these were somewhat less than found in the GPi by Guridi et al. [11] and comparable to those found by Priori et al. [30].

The position of the STN-middle with respect to the MRIbased target yielded a normal distribution with an SD of $1.6 \mathrm{~mm}$, which is almost equal to the SD of the depth of the implanted electrode $(1.5 \mathrm{~mm})$. Thus, this variance may reflect to a certain extend the accuracy of MRI imaging and also seems reasonable taking into account the MRI slice thickness of $1 \mathrm{~mm}[12,30]$. With respect to the required depth of the permanent electrode, Fig. 4a shows that the mean value of the calculated STN-middle derived from the intraoperatively recorded MER activity is in good agreement with the pre-operatively calculated depth of the target nucleus using MRI-based planning with the SchaltenbrandWahren atlas target coordinates [10, 34]. In case contact point 1 is placed at a depth that is only given by the MRI- 
a

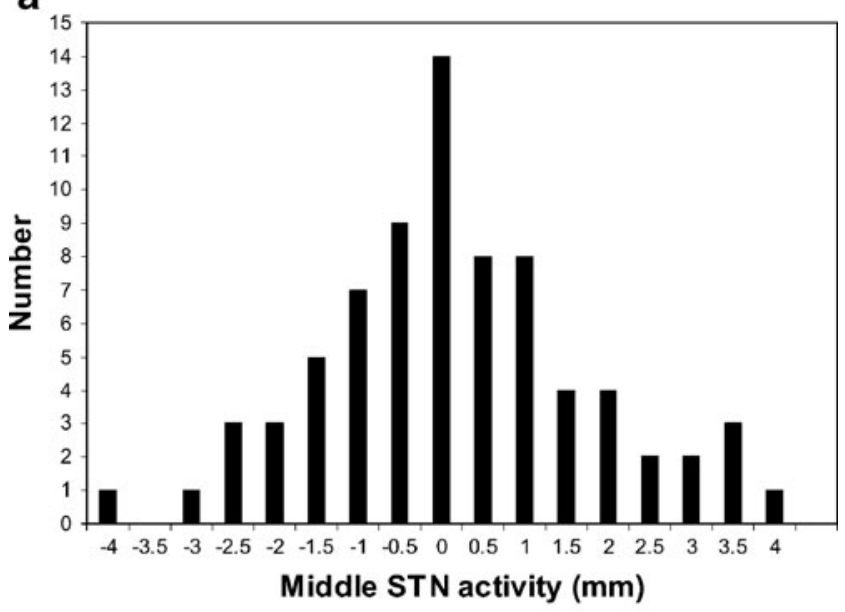

b

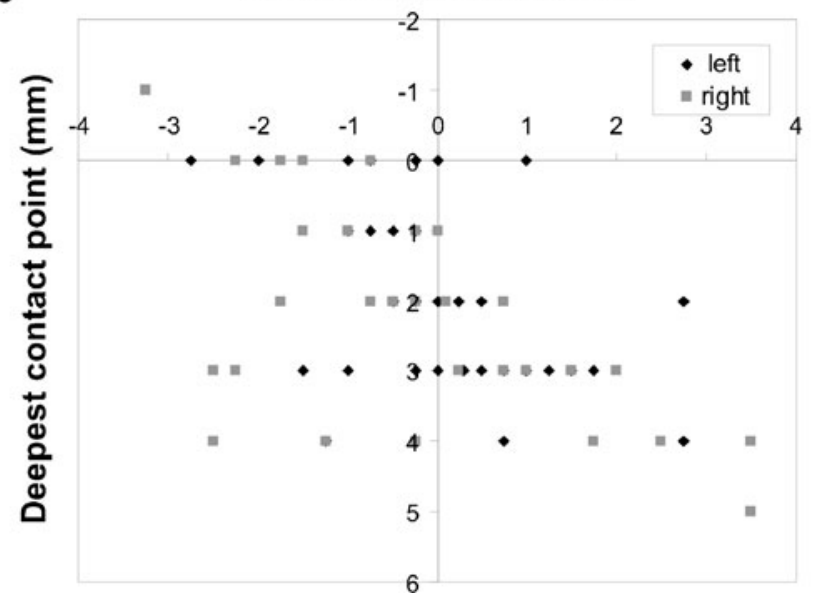

Fig. 4 a Frequency distribution of the STN-middle of the MER activity with respect to the MRI-based STN target. Mean $=0.0 \mathrm{~mm}$; $\mathrm{SD}=1.5 \mathrm{~mm}$. b Scatter plot of the relationship between the STNmiddle of the MER activity (horizontal) and the final depth of the deepest contact point (vertical) with respect to the MRI-based STN target. Data of right and left STN are pooled

based target, due to the variance in the depth of the STN, not all contact points will be necessarily situated inside the STN and, therefore, not the best functional target will be stimulated $[8,13,23,28,32,33]$. The implantable electrode consists of four contact points with a separation of $2 \mathrm{~mm}$ between the centers of two successive contact points, thus, according Fig. $4 \mathrm{a}$, in about $85 \%$ of the cases, at least two contact points would lie inside the STN, if only the MRIbased target should have been used.

The SD of the depth of the implanted electrode in the GPi of $1.2 \mathrm{~mm}$ was somewhat less than the one of $1.5 \mathrm{~mm}$ in the STN. This may be due to the fact that the MRI-based GPi target can be better determined than the MRI-based STN target. The SD of the GPi target in the current study is somewhat less than found by others $[12,27]$ and the SD of the STN target comparable to those found by Priori et al. [30].
Based on the observed MER activity in multiple channels, a pre-selection could be made as to which channel would be the best candidate for macro-test stimulation and at which depth should be stimulated [29]. After MER and macro-test stimulation, in $50 \%$ of the cases for the STN and in $57 \%$ for the GPi, the central channel was chosen for electrode implantation. The percentage of 50\% for the STN could have been even smaller if all insertions were measured with five channels. Thus, considering the results of Temel et al. [36], in which a percentage of $34 \%$ for left and right STN was found, our study confirms that, for STN, it is often deviated from the central channel for implantation. Furthermore, it was found that, whereas other channels showed STN MER activity, in $9 \%(9 / 98)$, the central channel did not show MER activity. The final position of the STN target in the axial plane corresponded in $64 \%$ of the cases with the STN target having the best MER activity and for the GPi target, this was so in $61 \%$ of the cases.

For MER and macro-test stimulation, some extra time was needed to attach the microdrive for the microelectrodes, connect the wires to the needles, and check for integrity of the system and stability of the signals. For STN and GPi, MER was started 8 and $12 \mathrm{~mm}$ above the calculated target depth, respectively. This resulted in about 25 recordings of $10 \mathrm{~s}$ each per site, which took about a period of $10 \mathrm{~min}$. Then, a summary of recordings was evaluated in order to decide in which channels and at what depths test stimulation should be performed. In comparison to the DBS procedure without MER, the time needed for the test procedure was thereafter reduced significantly, as stimulation was only started in two or three channels that had sufficient MER activity. In addition, if during macrotest stimulation one of the channels yielded worse results than others, testing on this particular channel was discontinued. Considering the accuracy of the MRI-based target, the period of MER could be shortened by starting recording at $6-\mathrm{mm}$ instead of $8-\mathrm{mm}$ distance from the MRI-based STN target and $100-\mathrm{mm}$ instead of 12-mm distance from the MRI-based ventral border of the GPi.

In bilaterally operated patients, we noted a non-significant trend towards a less frequent choice for the central channel on the side operated second (right). Significance possibly would have been reached with a larger patient population. This possible less accurate coincidence between MRI planning and MER registration on the second operative side may be due to cerebral fluid (CSF) loss and subsequent subdural air invasion during surgery in some cases, potentially causing brain displacement [9]. Great care, thus, should be taken to minimize CSF loss, especially when using multiple parallel microelectrodes that require wider opening of the dura matter than a single electrode. At the same time, MER provides direct target recognition and may allow for correction of stereotactic errors including brain displacement. 
In the current study population, one patient suffered from a clinically symptomatic hemorrhage (1\%). This raises the question whether the use of multiple trajectories through the brain in MER could potentially lead to an increased risk of hemorrhage. Others conclude that the incremental risk of multiple microelectrode penetrations was small [5], or it was not possible to demonstrate it given the sample sizes [36]. However, multiple passes through the brain are likely to be associated with an increased risk of hemorrhage $[6,15]$. Measures can be taken to reduce this risk, the most important ones being careful path-planning, avoiding vascular structures, and the prevention of CSF leakage during the procedure so that no shearing forces are applied on the brain by the cannulas due to brain shift. To reduce the risk of multiple insertions, one could omit one or two channels for MER. This can be decided on during the MRI planning. For instance, our study shows that, for the STN, only in $6 \%$ was the medial electrode used for implantation. With respect to the GPi, the anterior and the posterior channels were used for implantation in only $2 \%$ and $6 \%$, respectively.

Although this study demonstrates that MER improves targeting, inherent to the setup of this retrospective study, it is not possible to demonstrate any postoperative clinical improvement due to the use of MER. However, if postoperative clinical results are not satisfactory, with MER registration, inappropriate targeting is the less probable cause.

In summary, it is concluded from our 4 years experience that MER facilitates the selection of the final electrode location in STN-DBS and GPi-DBS and demonstrates that frequently (about $52 \%$ ), it is not the central channel that is chosen. However, in approximately $33 \%$ of the STN cases, the final position of the implanted electrode does not coincide with the position of optimal MER activity. On the other hand, for both the STN and GPi, on average, there is a good fit between the MER activity and the MRIbased targets with a mean of $0 \mathrm{~mm}$ and an SD of $1.5 \mathrm{~mm}$, which means that $95 \%$ of the targets fall within a range of $6 \mathrm{~mm}$.

Finally, it is suggested that, if MER is being used, probably less than five channels are necessary and MER could also be started closer than 8 and $12 \mathrm{~mm}$ for the MRIbased STN target and GPi target, respectively.

Conflicts of interest Dr. Lo J. Bour is a consultant for Philips Research.

Open Access This article is distributed under the terms of the Creative Commons Attribution Noncommercial License which permits any noncommercial use, distribution, and reproduction in any medium, provided the original author(s) and source are credited.

\section{References}

1. Alterman RL, Sterio D, Beric A, Kelly PJ (1999) Microelectrode recording during posteroventral pallidotomy: impact on target selection and complications. Neurosurgery 44:315-321

2. Benabid AL, Koudsie A, Benazzouz A, Vercueil L, Fraix V, Chabardes S, LeBas JF, Pollak P (2001) Deep brain stimulation of the corpus luysi (subthalamic nucleus) and other targets in Parkinson's disease. Extension to new indications such as dystonia and epilepsy. J Neurol 248(Suppl 3):III37-III47

3. Benabid AL, Krack PP, Benazzouz A, Limousin P, Koudsie A, Pollak P (2000) Deep brain stimulation of the subthalamic nucleus for Parkinson's disease: methodologic aspects and clinical criteria. Neurology 55:S40-S44

4. Benazzouz A, Breit S, Koudsie A, Pollak P, Krack P, Benabid AL (2002) Intraoperative microrecordings of the subthalamic nucleus in Parkinson's disease. Mov Disord 17(Suppl 3):S145S149

5. Binder DK, Rau GM, Starr PA (2005) Risk factors for hemorrhage during microelectrode-guided deep brain stimulator implantation for movement disorders. Neurosurgery 56:722-732

6. de Bie RM, de Haan RJ, Schuurman PR, Esselink RA, Bosch DA, Speelman JD (2002) Morbidity and mortality following pallidotomy in Parkinson's disease: a systematic review. Neurology 58:1008-1012

7. Dolan K, Martens HC, Schuurman PR, Bour LJ (2009) Automatic noise-level detection for extra-cellular micro-electrode recordings. Med Biol Eng Comput 47:791-800

8. Duque P, Mateo O, Ruiz F, de Viloria JG, Contreras A, Grandas F (2008) Intraoperative microrecording under general anaesthesia with bispectral analysis monitoring in a case of deep brain stimulation surgery for Parkinson's disease. Eur J Neurol 15:e76e77

9. Elias WJ, Fu KM, Frysinger RC (2007) Cortical and subcortical brain shift during stereotactic procedures. J Neurosurg 107:983988

10. Esselink RA, de Bie RM, de Haan RJ, Steur EN, Beute GN, Portman AT, Schuurman PR, Bosch DA, Speelman JD (2006) Unilateral pallidotomy versus bilateral subthalamic nucleus stimulation in Parkinson's disease: one year follow-up of a randomised observer-blind multi centre trial. Acta Neurochir (Wien) 148:1247-1255

11. Guridi J, Gorospe A, Ramos E, Linazasoro G, Rodriguez MC, Obeso JA (1999) Stereotactic targeting of the globus pallidus internus in Parkinson's disease: imaging versus electrophysiological mapping. Neurosurgery 45:278-287

12. Guridi J, Rodriguez-Oroz MC, Ramos E, Linazasoro G, Obeso JA (2002) Discrepancy between imaging and neurophysiology in deep brain stimulation of medial pallidum and subthalamic nucleus in Parkinson's disease. Neurologia 17:183-192

13. Hamel W, Fietzek U, Morsnowski A, Schrader B, Herzog J, Weinert D, Pfister G, Muller D, Volkmann J, Deuschl G, Mehdorn HM (2003) Deep brain stimulation of the subthalamic nucleus in Parkinson's disease: evaluation of active electrode contacts. J Neurol Neurosurg Psychiatry 74:1036-1046

14. Hamel W, Fietzek U, Morsnowski A, Schrader B, Weinert D, Muller D, Deuschl G, Mehdorn HM (2003) Subthalamic nucleus stimulation in Parkinson's disease: correlation of active electrode contacts with intraoperative microrecordings. Stereotact Funct Neurosurg 80:37-42

15. Hariz MI (2002) Safety and risk of microelectrode recording in surgery for movement disorders. Stereotact Funct Neurosurg 78:146-157

16. Hariz MI, Fodstad H (1999) Do microelectrode techniques increase accuracy or decrease risks in pallidotomy and deep brain 
stimulation? A critical review of the literature. Stereotact Funct Neurosurg 72:157-169

17. Hashimoto T (2004) Microrecording: a guide to stereotactic brain operations. No Shinkei Geka 32:297-303

18. Hayase N, Miyashita N, Endo K, Narabayashi H (1998) Neuronal activity in GP and Vim of parkinsonian patients and clinical changes of tremor through surgical interventions. Stereotact Funct Neurosurg 71:20-28

19. Hutchison WD, Allan RJ, Opitz H, Levy R, Dostrovsky JO, Lang AE, Lozano AM (1998) Neurophysiological identification of the subthalamic nucleus in surgery for Parkinson's disease. Ann Neurol 44:622-628

20. Kim MS, Jung YT, Sim JH, Kim SJ, Kim JW, Burchiel KJ (2006) Microelectrode recording: lead point in STN-DBS surgery. Acta Neurochir Suppl 99:37-42

21. Krack P, Batir A, Van BN, Chabardes S, Fraix V, Ardouin C, Koudsie A, Limousin PD, Benazzouz A, LeBas JF, Benabid AL, Pollak P (2003) Five-year follow-up of bilateral stimulation of the subthalamic nucleus in advanced Parkinson's disease. N Engl J Med 349:1925-1934

22. Lozano A, Hutchison W, Kiss Z, Tasker R, Davis K, Dostrovsky J (1996) Methods for microelectrode-guided posteroventral pallidotomy. J Neurosurg 84:194-202

23. Lozano AM, Hutchison WD (2002) Microelectrode recordings in the pallidum. Mov Disord 17(Suppl 3):S150-S154

24. Lozano AM, Hutchison WD, Dostrovsky JO (1995) Microelectrode monitoring of cortical and subcortical structures during stereotactic surgery. Acta Neurochir Suppl 64:30-34

25. Merello M, Cerquetti D, Cammarota A, Tenca E, Artes C, Antico J, Leiguarda R (2004) Neuronal globus pallidus activity in patients with generalised dystonia. Mov Disord 19:548-554

26. Merello M, Tenca E, Cerquetti D (2006) Neuronal activity of the zona incerta in Parkinson's disease patients. Mov Disord 21:937-943

27. Molinuevo JL, Valldeoriola F, Valls-Sole J (2003) Usefulness of neurophysiologic techniques in stereotactic subthalamic nucleus stimulation for advanced Parkinson's disease. Clin Neurophysiol 114:1793-1799

28. Moran A, Bergman H, Israel Z, Bar-Gad I (2008) Subthalamic nucleus functional organization revealed by parkinsonian neuronal oscillations and synchrony. Brain 131:3395-3409

29. Pollak P, Krack P, Fraix V, Mendes A, Moro E, Chabardes S, Benabid AL (2002) Intraoperative micro- and macrostimulation of the subthalamic nucleus in Parkinson's disease. Mov Disord 17 (Suppl 3):S155-S161
30. Priori A, Egidi M, Pesenti A, Rohr M, Rampini P, Locatelli M, Tamma F, Caputo E, Chiesa V, Barbieri S (2003) Do intraoperative microrecordings improve subthalamic nucleus targeting in stereotactic neurosurgery for Parkinson's disease? J Neurosurg Sci 47:56-60

31. Rodriguez-Oroz MC, Rodriguez M, Guridi J, Mewes K, Chockkman V, Vitek J, DeLong MR, Obeso JA (2001) The subthalamic nucleus in Parkinson's disease: somatotopic organization and physiological characteristics. Brain 124:1777-1790

32. Romanelli P, Esposito V, Schaal DW, Heit G (2005) Somatotopy in the basal ganglia: experimental and clinical evidence for segregated sensorimotor channels. Brain Res Brain Res Rev 48:112-128

33. Romanelli P, Heit G, Hill BC, Kraus A, Hastie T, Bronte-Stewart HM (2004) Microelectrode recording revealing a somatotopic body map in the subthalamic nucleus in humans with Parkinson disease. J Neurosurg 100:611-618

34. Speelman JD, Schuurman R, de Bie RM, Esselink RA, Bosch DA (2002) Stereotactic neurosurgery for tremor. Mov Disord 17(Suppl 3):S84-S88

35. Tang JK, Moro E, Mahant N, Hutchison WD, Lang AE, Lozano AM, Dostrovsky JO (2007) Neuronal firing rates and patterns in the globus pallidus internus of patients with cervical dystonia differ from those with Parkinson's disease. J Neurophysiol 98:720-729

36. Temel Y, Wilbrink P, Duits A, Boon P, Tromp S, Ackermans L, van Kranen-Mastenbroek V, Weber W, Visser-Vandewalle V (2007) Single electrode and multiple electrode guided electrical stimulation of the subthalamic nucleus in advanced Parkinson's disease. Neurosurgery 61:346-355

37. Theodosopoulos PV, Marks WJ Jr, Christine C, Starr PA (2003) Locations of movement-related cells in the human subthalamic nucleus in Parkinson's disease. Mov Disord 18:791-798

38. Vitek JL, Bakay RA, Hashimoto T, Kaneoke Y, Mewes K, Zhang JY, Rye D, Starr P, Baron M, Turner R, DeLong MR (1998) Microelectrode-guided pallidotomy: technical approach and its application in medically intractable Parkinson's disease. J Neurosurg 88:1027-1043

39. Vitek JL, Chockkan V, Zhang JY, Kaneoke Y, Evatt M, DeLong MR, Triche S, Mewes K, Hashimoto T, Bakay RA (1999) Neuronal activity in the basal ganglia in patients with generalized dystonia and hemiballismus. Ann Neurol 46:22-35

40. Zhuang P, Li YJ (2003) Characteristics of subthalamic neuronal activities in Parkinson's disease. Sheng Li Xue Bao 55:435-441 